\title{
Does low-level laser therapy enhance the efficacy of intravenous regional anesthesia?
}

\author{
Sholeh Nesioonpour MD ${ }^{1,2}$, Reza Akhondzadeh MD,2, Soheila Mokmeli MD ${ }^{3}$, Shahnam Moosavi MD ${ }^{4}$, \\ Mandana Mackie $\mathrm{MD}^{1,2}$, Morteza Naderan $\mathrm{MD}^{5}$
}

S Nesioonpour, R Akhondzadeh, S Mokmeli, S Moosavi, M Mackie, M Naderan. Does low-level laser therapy enhance the efficacy of intravenous regional anesthesia? Pain Res Manag 2014;19(6):e154e158.

BACKGROUND: The use of intravenous regional anesthesia (IVRA) is limited by pain resulting from the application of tourniquets and postoperative pain.

OBJECTIVE: To assess the efficacy of low-level laser therapy added to IVRA for improving pain related to surgical fixation of distal radius fractures. METHODS: The present double-blinded, placebo-controlled, randomized clinical trial involved 48 patients who were undergoing surgical fixation of distal radius fractures. Participants were randomly assigned to either an intervention group $(\mathrm{n}=24)$, who received $808 \mathrm{~nm}$ laser irradiation as $4 \mathrm{~J} /$ point for $20 \mathrm{~s}$ over ipsilateral three nerve roots in the cervical region corresponding to $\mathrm{C} 5-\mathrm{C} 8$ vertebrae, and $808 \mathrm{~nm}$ laser irradiation as $0.1 \mathrm{~J} / \mathrm{cm}^{2}$ for $5 \mathrm{~min}$ in a tangential scanning mode over the affected extremity; or a control group $(n=24)$, who underwent the same protocol and timing of laser probe application with the laser switched off. Both groups received the same IVRA protocol using $2 \%$ lidocaine.

RESULTS: The mean visual analogue scale scores were significantly lower in the laser-assisted group than in the lidocaine-only group on all measurements during and after operation $(\mathrm{P}<0.05)$. The mean time to the first need for fentanyl administration during the operation was longer in the laser group $(\mathrm{P}=0.04)$. The total amount of fentanyl administered to patients was significantly lower in the laser-assisted group $(\mathrm{P}=0.003)$. The laser group needed significantly less pethidine for pain relief $(\mathrm{P}=0.001)$ and at a later time $(\mathrm{P}=0.002)$ compared with the lidocaine-only group. There was no difference between the groups in terms of mean arterial pressure and heart rate.

CONCLUSION: The addition of gallium-aluminum-arsenide laser irradiation to intravenous regional anesthesia is safe, and reduces pain during and after the operation.

Key Words: Distal radius fracture; Intravenous regional anesthesia; Low-level laser therapy; Postoperative pain; Tourniquet

Tntravenous regional anesthesia (IVRA) is mainly used in surgical 1 operations with predicted durations of $<1 \mathrm{~h}$. Although this technique is useful for fractures of the upper extremity, especially distal to the elbow, and relieves the need for general anesthesia, it is limited by pain resulting from the application of tourniquets and postoperative pain (1-3). Increasing the efficacy of pain control in IVRA has been attempted by several authors, who have studied the addition of drugs, such as dexmedetomidine, dexamethasone, ketorolac and melatonin, to lidocaine in IVRA protocols, and reported enhanced anesthesia time and reduced pain perceived by patients (4-7).

Rather than these pharmacological interventions, we have used low-level laser therapy (LLLT) as an adjunct to the standard IVRA protocol. In recent years, and following Food and Drug Administration

\section{Le traitement au laser à basse énergie améliore-t-il l'efficacité de l'anesthésie régionale intraveineuse?}

HISTORIQUE : L'anesthésie régionale intraveineuse (ARIV) est limitée par la douleur découlant de l'application des tourniquets et par la douleur postopératoire.

OBJECTIF : Évaluer l'efficacité du traitement au laser à basse énergie ajoutée à l'ARIV pour soulager la douleur liée à la réduction chirurgicale d'une fracture du radius distal.

MÉTHODOLOGIE : La présente étude clinique aléatoire à double insu contrôlée contre placebo portait sur 48 candidats qui subissaient une réduction chirurgicale de fracture du radius distal. Les participants ont été répartis au hasard entre un groupe d'intervention $(n=24)$ qui ont reçu une irradiation au laser de $808 \mathrm{~nm}$ à $4 \mathrm{~J} /$ point pendant 20 secondes sur trois racines nerveuses ipsilatérales de la région cervicale, correspondant aux vertèbres $\mathrm{C} 5$ à C8, et une irradiation au laser de $808 \mathrm{~nm}$ à $0,1 \mathrm{~J} / \mathrm{cm}^{2}$ pendant 5 minutes en mode de numérisation tangentielle sur le membre touché. Le groupe témoin $(n=24)$ a subi le même protocole et la même durée d'application de la sonde laser, mais le laser était éteint. Les deux groupes ont été soumis au même protocole d'ARIV à l'aide de lidocaïne $2 \%$.

RÉSULTATS : Les indices moyens de l'échelle analogique visuelle étaient considérablement plus faibles dans le groupe ayant subi le traitement au laser que dans celui ayant reçu seulement de la lidocaïne à l'égard de toutes les mesures pendant et après l'opération $(\mathrm{P}<0,05)$. Le délai moyen avant qu'il soit nécessaire d'administrer du fentanyl pendant l'opération était plus long dans le groupe ayant reçu le traitement au laser $(\mathrm{P}=0,04)$. La quantité totale de fentanyl administrée aux patients était beaucoup plus faible dans ce groupe $(\mathrm{P}=0,003)$, qui avait besoin de beaucoup moins de péthidine pour soulager la douleur $(\mathrm{P}=0,001)$ et en prenait plus tard $(\mathrm{P}=0,002)$ que le groupe n'ayant reçu que de la lidocaïne. On ne constatait pas de différence entre les groupes pour ce qui est de la pression artérielle moyenne et du rythme cardiaque.

CONCLUSION : L'ajout d'une irradiation au laser à l'arséniure de gallium et d'aluminium à l'ARIV est sécuritaire et atténue la douleur pendant et après l'opération.

approval of LLLT $(8,9)$ for pain relief, the practice has become relatively common. Although the exact mechanism of LLLT is not fully understood, there is evidence that LLLT activates many local analgesic mechanisms that affect perception of pain $(10,11)$. Thus, some researchers have implemented the LLLT protocols in their studies to determine whether this approach is effective in pain management. For example, low-power irradiation was successfully used to treat pain due to lateral elbow tendinopathy (12) and pain associated with knee osteoarthritis (13). Postoperative pain management has also been studied in attempts to provide evidence in favour of or against the efficacy of LLLT in surgical settings. For instance, pain management and administration of analgesics were improved after low-power red laser irradiation in breast augmentation surgery (14), cryosurgical

${ }^{1}$ Pain Research Center; ${ }^{2}$ Department of Anesthesiology, Ahvaz Jundishapur University of Medical Sciences, Ahvaz, Iran; ${ }^{3}$ Canadian Optic $\mathcal{E}^{2}$ Laser Production Center, British Columbia; ${ }^{4}$ Department of Orthopedics, Ahvaz Jundishapur University of Medical Sciences, Ahvaz; ${ }^{5}$ Farzan Clinical Research Institute, Tehran, Iran

Correspondence: Sholeh Nesioonpour, Department of Anesthesiology, Ahvaz Jundishapur University of Medical Sciences, Azadegan Avenue, Imam Khomeini Hospital, Ahvaz, Iran. Telephone 98-91-6311-6324, fax 98-61-1222-0168, e-mail nesioonpour-sh@ajums.ac.ir 
TABLE 1

\section{Exclusion criteria for the study population}

Reynaud's phenomenon
Systemic sclerosis
Sickle cell anemia
Diabetes mellitus
Renal failure
Hepatic dysfunction
Pregnancy
Malignancy
Benign tumours with malignant potential
Photosensitivity (eg, systemic lupus erythematosus)
History of convulsions

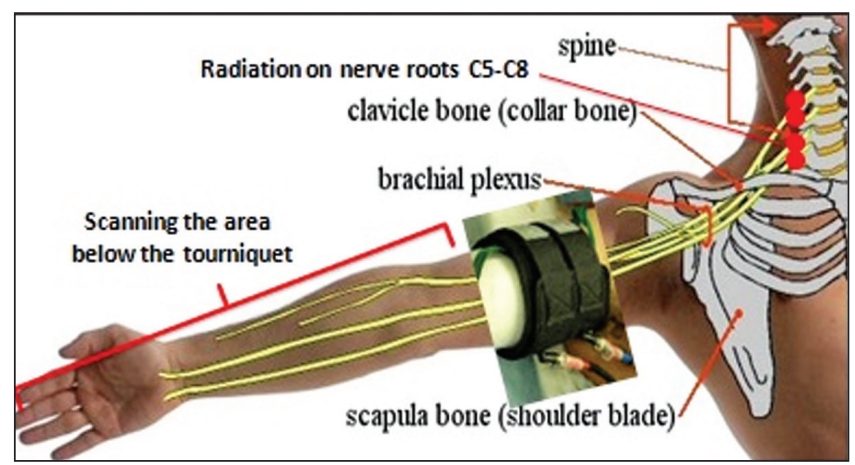

Figure 1) The points and locations irradiated in the patients

treatment of leukoplakia (15) and cholecystectomy (16). LLLT was also beneficial in reducing complications of surgical procedures such as lymphedema after mastectomy $(17,18)$.

The aim of the present study was to assess the efficacy of pretreatment with gallium-aluminum-arsenide (Ga-Al-As) irradiation as an adjunct to IVRA in terms of the pain perceived by patients during and after the operation, and the need for opioid administration in the surgical fixation of distal radius fractures.

\section{METHODS}

The present study was a double-blinded, placebo-controlled, randomized clinical trial involving 48 patients with distal radius fracture eligible for pin-casting surgery (code: IRCT2012081810509N3). To the authors' knowledge, the present study is the first to publish such results. The present study was conducted at the Imam Khomeini Hospital, Ahvaz, Iran, from 2012 to 2013. The Ethics Committee of Jundishapur University of Medical Sciences (Ahvaz, Iran) approved the study, and informed written consent was obtained from all participants after full disclosure of the purpose of the study (code: ETH-441). The inclusion criteria were based on the American Society of Anesthesiology physical status classification system. Patients who were classified as American Society of Anesthesiology physical status class I or II, with distal radius fracture, who were between 18 and 50 years of age were included in the study. Exclusion criteria are presented in Table 1.

Using a random numbers table and random digits, participants were assigned to two groups: a placebo (ie, control) group $(n=24)$ and a laserassisted group $(n=24)$. The study was double blinded - the patients and therapist (anesthesia resident) who completed the questionnaires were blinded to the patient groups and did not know the study groups. Only the operator of the LLLT was aware of the study group.

The method used to provide anesthesia was essentially the same for both groups. An intravenous (IV) line was established in the dorsal vein of the fractured extremity as distal as possible to the surgical site to inject anesthetics. Another IV line was placed in the other hand to infuse crystalloid fluids and $0.03 \mathrm{mg} / \mathrm{kg}$ midazolam. To vacate blood from the surgical site, the affected upper limb was elevated for $2 \mathrm{~min}$
TABLE 2

Baseline characteristics of the study population

\begin{tabular}{lccc}
\hline & \multicolumn{2}{c}{ Group (n=24) } & \\
\cline { 2 - 3 } Characteristic & Laser assisted & Lidocaine only & P \\
\hline Age, years & $35.3 \pm 8.9$ & $34.5 \pm 7.8$ & 0.7 \\
Sex, $\mathrm{n}(\%)$ & & & \\
$\quad$ Male & $21(87.5)$ & $17(70.83)$ & \\
$\quad$ Female & $3(12.5)$ & $7(29.16)$ & \\
Weight, kg & $71.04 \pm 6.9$ & $71.6 \pm 6.6$ & 0.76 \\
Height, cm & $168.7 \pm 5.38$ & $168.5 \pm 5.59$ & 0.89 \\
Duration of & $39.7 \pm 6.8$ & $41.3 \pm 5.9$ & 0.4 \\
inflation, min & & & \\
\hline
\end{tabular}

Data presented as mean $\pm S D$ unless otherwise indicated

and then wrapped with an elastic band. Subsequently, a double-cuffed tourniquet was applied around the upper arm. The proximal cuff was inflated to $300 \mathrm{mmHg}$ immediately before removing the elastic band. The absence of radial artery pulses and pulse oximetry waves were considered to be evidence of the success of this procedure. Both groups received $2 \%$ lidocaine $(3 \mathrm{mg} / \mathrm{kg}$, diluted by normal saline to $40 \mathrm{~mL}$ ) through an intravenous line in the affected extremity (Aburaihan Pharmaceutical Co, Iran).

The laser-assisted group received irradiation via a continuouswave Ga-Al-As device (Canadian Optic and Laser Production Center, Canada). The specifications of this device include the following: wavelength $808 \mathrm{~nm}$, power $200 \mathrm{~mW}$, power density $0.8 \mathrm{~W} / \mathrm{cm}^{2}$ and contact area $0.25 \mathrm{~cm}^{2}$. Immediately after the proximal cuff was inflated, patients received $4 \mathrm{~J} /$ point contact laser irradiation over three nerve roots from C5 to C8 vertebrae on the affected side, for $20 \mathrm{~s}$ over each point. Furthermore, they received $0.1 \mathrm{~J} / \mathrm{cm}^{2}$ tangential scanning irradiation on the affected limb for a total of $5 \mathrm{~min}$ from the lower border of the tourniquet through the forearm, wrist and fingers (Figure 1). The control group received the same protocol and timing of laser probe application with the laser switched off. Sensory block was tested every $30 \mathrm{~s}$ by pinprick test ( 22 gauge) in the median, lateral cutaneous, ulnar and radial nerve territories. When complete anesthesia was achieved, the distal cuff was inflated to $300 \mathrm{mmHg}$ and the proximal cuff was deflated.

$\mathrm{O}_{2}$ saturation, mean arterial pressure (MAP) and heart rate (HR) were measured before and immediately after inflation of the distal cuff, and then every $10 \mathrm{~min}$ for five additional measurements. The time to first request for pain relief by the patient was recorded. Moreover, pain severity was measured using a visual analogue scale (VAS) within the operation. If the VAS score was $\geq 3,1 \mu \mathrm{g} / \mathrm{kg}$ fentanyl was infused immediately. If pain was not controlled adequately, general anesthesia was implemented and the patient was excluded from the study. The total surgical duration, duration of cuff inflation and total amount of fentanyl administered to patients were recorded. The cuff was not deflated before $30 \mathrm{~min}$ and was not kept inflated for $>90 \mathrm{~min}$. The deflation was implemented every $10 \mathrm{~s}$ at the end of operation. If the postoperative VAS score was $>3,20 \mathrm{mg}$ pethidine was injected intravenously. The time to first request for postoperative pain relief and the total amount of pethidine administered were recorded in the $24 \mathrm{~h}$ after the operation.

Patients were evaluated for possible side effects such as hypertension or hypotension, bradycardia or tachycardia, hypoxia, tinnitus, headache, nausea and vomiting, vertigo, fatigue, arrhythmia, somnolence, bleeding at the site of operation and paresthesia.

The following statistics were used for calculating sample size:

$$
\mathrm{N}=\frac{\left(Z_{1-\frac{a}{z}}+Z_{1-\beta}\right)^{2}\left(P_{1}\left(1-P_{1}\right)+P_{2}\left(1-P_{2}\right)\right)}{\left(P_{1}-P_{2}\right)^{2}}
$$

$95 \%$ confidence with $80 \%$ power was assigned and, according to previous studies, $\mathrm{P}_{1}=74$ and $\mathrm{P}_{2}=37$ (13). 
TABLE 3

Heart rate and mean arterial pressure of the participants during operation

\begin{tabular}{|c|c|c|c|c|c|c|}
\hline \multirow[b]{2}{*}{ Time interval } & \multicolumn{3}{|c|}{ Heart rate } & \multicolumn{3}{|c|}{ Mean arterial pressure } \\
\hline & Laser assisted & Lidocaine only & $\mathbf{P}$ & Laser assisted & Lidocaine only & $\mathbf{P}$ \\
\hline Before inflation & $87.5 \pm 9.13$ & $84.7 \pm 9.07$ & 0.2 & $102.31 \pm 9.6$ & $102.97 \pm 7.02$ & 0.78 \\
\hline After inflation & $89.04 \pm 9.34$ & $87.1 \pm 9.16$ & 0.06 & $100.6 \pm 5.7$ & $99.41 \pm 9.51$ & 0.6 \\
\hline $5 \mathrm{~min}$ & $89.7 \pm 7.08$ & $86.7 \pm 9.01$ & 2 & $101.6 \pm 11$ & $99.5 \pm 8.7$ & 0.6 \\
\hline $10 \min$ & $87.87 \pm 6.47$ & $87.29 \pm 8.81$ & 0.79 & $96.03 \pm 10.1$ & $100.59 \pm 7.17$ & 0.8 \\
\hline $20 \mathrm{~min}$ & $90.29 \pm 6.5$ & $88.9 \pm 5.7$ & 0.4 & $97.83 \pm 11.2$ & $101.38 \pm 7.9$ & 0.21 \\
\hline $30 \mathrm{~min}$ & $89.6 \pm 6.1$ & $86.5 \pm 7.4$ & 0.13 & $96.2 \pm 12$ & $101.04 \pm 8.9$ & 0.12 \\
\hline $40 \mathrm{~min}$ & $90.2 \pm 8$ & $87.9 \pm 7.1$ & 0.3 & $96.5 \pm 13.7$ & $102.1 \pm 8.7$ & 0.09 \\
\hline $50 \mathrm{~min}$ & $90.95 \pm 7.6$ & $87.7 \pm 6.7$ & 0.12 & $98.16 \pm 10.39$ & $102.1 \pm 9.02$ & 0.16 \\
\hline
\end{tabular}

Data presented as mean $\pm S D$ unless otherwise indicated

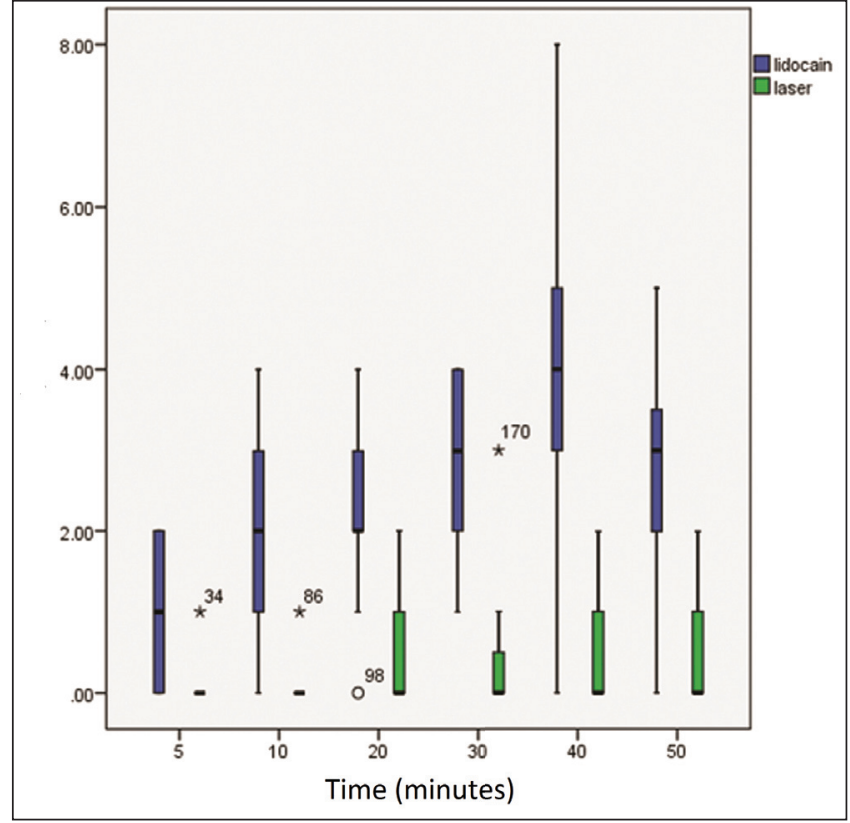

Figure 2) Schematic comparison of visual analogue scale scores between the lidocaine-only group (blue) and the laser-assisted group (green) during operation. Vertical axis shows visual analogue scale scores and horizontal axis shows time in $\mathrm{min}$

Data were analyzed using SPSS version 20 (IBM Corporation, USA). $t$ tests and $\chi^{2}$ tests were used for comparison of quantitative and qualitative results, respectively.

\section{RESULTS}

A total of 48 participants completed the study. Anthropometric characteristics of the study population are presented in Table 2. Men outnumbered women by threefold $(77.1 \%$ versus $22.9 \%)$, which may be accounted for by traumatic events occurring in this age group.

MAP and HR were measured just before and after inflation of the tourniquet, and at $5 \mathrm{~min}, 10 \mathrm{~min}, 20 \mathrm{~min}, 30 \mathrm{~min}, 40 \mathrm{~min}$ and $50 \mathrm{~min}$ into the operation. The analysis demonstrated that there was no significant difference between the lidocaine-only group and the laserassisted group in terms of MAP and HR (Table 3). The arterial saturation of $\mathrm{O}_{2}$ was $100 \%$ at all measurements in both groups.

The level of pain perceived by patients was assessed using a VAS. The measurements were performed before and after inflation of the tourniquet, and $5 \mathrm{~min}, 10 \mathrm{~min}, 20 \mathrm{~min}, 30 \mathrm{~min}, 40 \mathrm{~min}$ and $50 \mathrm{~min}$ into the operation (Figure 2). Measurements were then extended to $2 \mathrm{~h}, 4 \mathrm{~h}, 8 \mathrm{~h}$, $12 \mathrm{~h}$ and $24 \mathrm{~h}$ after operation (Figure 3 ). No subjects reported pain before inflation of the tourniquet. The analysis showed significantly lower levels of pain in the laser-assisted group for all measurements (Table 4).

The mean time to the first request for pain relief during operation (fentanyl infusion) was $35 \pm 5 \mathrm{~min}$ for the laser-assisted group and

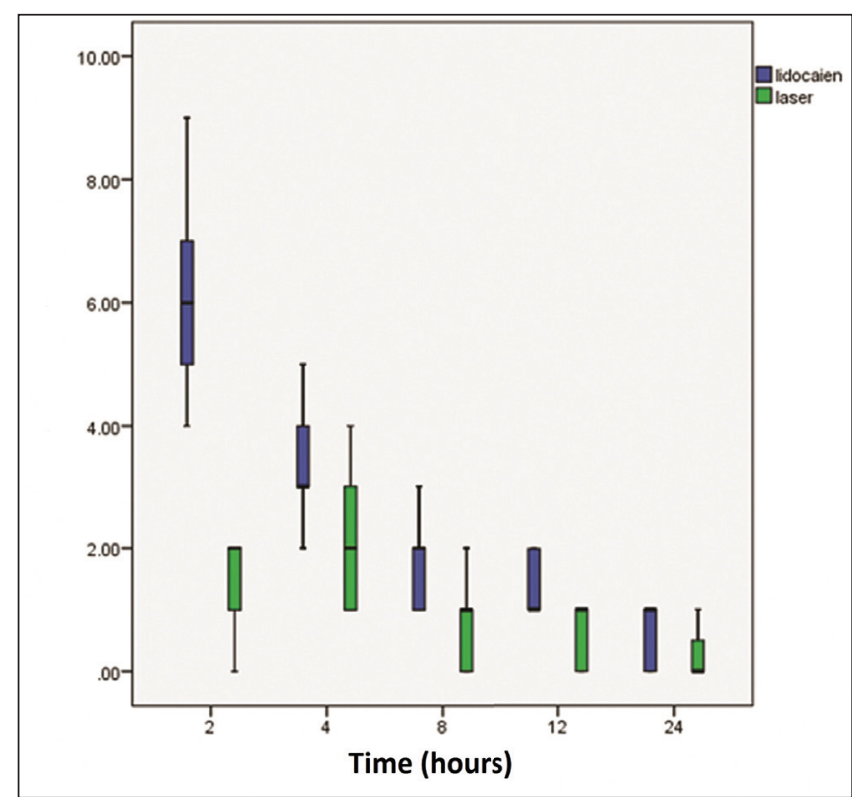

Figure 3) Schematic comparison of visual analogue scale scores between lidocaine-only group (blue) and laser-assisted group (green) after operation. The vertical axis shows visual analogue scale scores and the horizontal axis shows time in $h$

$15 \pm 6.87 \mathrm{~min}$ for the lidocaine-only group. This difference reached statistical significance $(\mathrm{P}=0.04)$; also, the total dose of fentanyl infused in the laser-assisted group was lower $(20.74 \pm 10.41 \mu \mathrm{g})$ than that of the lidocaine-only group $(104.16 \pm 44.02 \mu \mathrm{g})(\mathrm{P}=0.003)$. There was also a significant difference between groups in terms of the need for postoperative pain relief (pethidine injection). The mean time for the first request of pethidine was $186 \pm 45.6 \mathrm{~min}$ in the laser-assisted group and $24.05 \pm 23.7 \mathrm{~min}$ in the lidocaine-only group $(\mathrm{P}=0.002)$. The total amount of pethidine injected postoperatively was $13.3 \pm 11.2 \mathrm{mg}$ in the laser-assisted group and $38.3 \pm 18.5 \mathrm{mg}$ in the lidocaine-only group, which was significantly lower in the former $(\mathrm{P}=0.001)$.

\section{DISCUSSION}

The results of our study showed that adding Ga-Al-As laser irradiation $(808 \mathrm{~nm})$ to IV lidocaine enhances the efficacy of regional anesthesia in terms of perceived pain and reduction of the need for opioid agents. The IVRA is especially constrained by tourniquet-induced pain and the postoperative pain resulting from diminished effects of the lidocaine. Importantly, the laser-assisted group needed both fentanyl and pethidine for anesthesia at a later time during and after operation, respectively, than did the lidocaine-only group. The same conclusion could be drawn for the total dose of fentanyl and pethidine administered for pain management postoperatively. This may be considered to be the effects of the laser irradiation protocol. It is important to note that no side effects were reported by patients at any time during the study. 
The clinical application of LLLT for the treatment of acute and chronic pain is now well documented. Whereas the analgesic effects of LLLT has been studied for management of musculoskeletal pain and postoperative pain (10-16), our search revealed no published clinical trials regarding the addition of a laser protocol to IVRA in hand surgery. It has been shown that the pretreatment of the skin with a low-level laser followed by a $5 \mathrm{~min}$ topical lidocaine $4 \%$ diminished the pain of intravenous cannulation in adult and pediatric patients $(19,20)$. Laser therapy on surgical sites has been suggested to reduce the amount of analgesic drug consumption during surgery and pain after surgery. Jackson et al (14) studied 104 patients in Russia who underwent breast augmentation surgery and found that irradiation with a $630 \mathrm{~nm}$ to $640 \mathrm{~nm}$ low-power laser at the beginning and at the end of operation resulted in less postoperative pain and less analgesic consumption during the first week after surgery. In a controlled study by Moore et al (16) in England, 22 patients underwent cholecystectomy and received Ga-Al-As $(830 \mathrm{~nm})$ irradiation in a continuous mode. The results revealed a significant $50 \%$ reduction in postoperative pain in the laser group, with less analgesic consumption.

Koszowski et al (21) reported the comparison of analgesic effect of magnetic and laser stimulation before oral procedures. Laser stimulation and alternating magnetic field applied directly before oral surgery wereshown to be effective as analgesic agents to decrease intra- and postoperative sensations. Patients with high levels of stomatological fear were found to be more prone to sensation of pain; however, even in this group, laser and magnetic stimulation significantly reduced this complication. Results of a pilot study by Jonsson (22) demonstrated that fewer patients returned for postoperative redressing and complained of postoperative pain when laser therapy was offered as a part of surgical regimen to assist with postoperative healing after digital surgery (Winograd-type partial matrixectomy of the hallux).

The Food and Drug Administration's approval of the analgesic effect of laser therapy was motivation to assess its application as part of a perioperative plan for pain management. The most commonly used analgesic drugs after surgery are opioids and nonsteroidal antiinflammatory drugs (NSAIDs). All opioids have been used to produce analgesia either before or after surgery. Common side effects of opioids include problems with breathing, apnea, nausea and vomiting, sleepiness, difficulty in thinking clearly, constipation, gradual overdose, and synergism with sedatives, anticonvulsants and local anesthetics that may increase their respective side effects. The most common recovery complications are attributed to narcotics. NSAIDs are typically used after surgery and it is recognized that the use of NSAIDs increases the risk of gastrointestinal bleeding, heart attacks and strokes. Finding a safe analgesia method with no side effects is always a main goal for

\section{REFERENCES}

1. dos Reis A Jr. Intravenous regional anesthesia - first century (1908-2008): Beginning, development, and current status. Rev Bras Anestesiol 2008;58:299-321.

2. Brill S, Middleton W, Brill G, Fisher A. Bier's block: 100 years old and still going strong. Acta Anaesthesiol Scand 2004;48:117-22.

3. Miller RD. Nerve blocks. In: Miller RD, Eriksson LI, Fleisher LA, Wiener-Kronish JP, Young WL, eds. Miller's Anesthesia, 7th edition. Philadelphia: Churchill Livingstone/Elsevier; 2010:1648-9.

4. Memis D, Turan A, Karaman B, Pamukcu Z, Kurt I. Adding dexamedtomidine to lidocaine for intravenous regional anesthesia. Anesth Analg 2004;98:3835-40.

5. Biggat Z, Boztug N, Hadimioglu N, Cete N, Coskunfirat N, Ertok E. Does dexamethasone improve the quality of intravenous regional anesthesia and analgesia: A randomised, controlled clinical study. Anesth Analg 2006;102:2605-09.

6. Rivera JJ, Villecco DJ, Dehner BK, Burkarad JF, Osborne LA, Pellegrini JE. The efficacy of ketorolac as an adjunct to the Bier block for controlling postoperative pain following non-traumatic hand and wrist surgery. AANA J 2008;76:341-5.

7. Mowfi HA, Ismail SA. Melatonin improves tourniquet's tolerance and enhances postoperative analgesia in patients receiving intravenous regional anesthesia. Anesth Analg 2008;107:1422-6.

\section{TABLE 4}

Visual analogue scale scores during and after operation

\begin{tabular}{lccl}
\hline & \multicolumn{2}{c}{ Group ( $\mathbf{n}=\mathbf{2 4}$ per group) } & \\
\cline { 2 - 3 } Time interval & Laser assisted & Lidocaine only & \multicolumn{1}{c}{$\mathbf{P}^{*}$} \\
\hline $5 \mathrm{~min}$ & $0.2 \pm 0.04$ & $1.04 \pm 0.8$ & 0.04 \\
$10 \mathrm{~min}$ & $0.2 \pm 0.03$ & $2.08 \pm 1.24$ & 0.001 \\
$20 \mathrm{~min}$ & $0.58 \pm 0.45$ & $2.37 \pm 1.13$ & 0.02 \\
$30 \mathrm{~min}$ & $0.7 \pm 0.33$ & $3 \pm 0.97$ & 0.02 \\
$40 \mathrm{~min}$ & $0.77 \pm 0.54$ & $3.7 \pm 1.85$ & 0.03 \\
$50 \mathrm{~min}$ & $0.7 \pm 0.45$ & $2.58 \pm 1.34$ & 0.01 \\
$2 \mathrm{~h}$ postoperation & $1.41 \pm 0.71$ & $6.2 \pm 1.38$ & 0.03 \\
$4 \mathrm{~h}$ postoperation & $2 \pm 0.97$ & $3.45 \pm 0.88$ & 0.01 \\
$8 \mathrm{~h}$ postoperation & $0.83 \pm 0.63$ & $1.7 \pm 0.55$ & 0.001 \\
$12 \mathrm{~h}$ postoperation & $0.58 \pm 0.50$ & $1.37 \pm 0.49$ & 0.03 \\
24 h postoperation & $0.44 \pm 0.25$ & $0.66 \pm 0.48$ & 0.003 \\
\hline
\end{tabular}

Data presented as mean $\pm S D$ unless otherwise indicated. ${ }^{*} P<0.05$, statistically significant

anesthesiology. Laser therapy is an approved safe and noninvasive method for pain control, according to various studies. It appears that the summation of the analgesic effect of laser therapy and local anesthetic can increase the duration of anesthesia and the analgesic effect of drugs, while reducing drug consumption and, thus, eliminating complications due to drugs.

One limitation to our study was that we could not document the exact onset of sensory and motor block because of the elapsed time resulting from irradiation. Our study also did not determine whether long-term mobility outcomes were different between groups.

Over the past decade, considerable evidence has emerged for the positive effects of LLLT in the field of pain management. Here, we assessed this therapy in distal radius fractures and, according to our results, determined that addition of Ga-Al-As laser irradiation to lidocaine-induced regional anesthesia is an effective and safe means to reduce pain and analgesic consumption during hand surgery.

ACKNOWLEDGEMENTS: This article is issued from the thesis of Dr Mandana Mackie and financial support was provided by Ahvaz Jundishapur University of Medical Sciences (Grant No U-91009). The authors acknowledge the deputy vice-chancellor for research and technology affairs of Ahvaz Jundishapur University of Medical Sciences. No conflict of interest was present at any time, place or for any person, or regarding any device that was used in the study. The authors are grateful to the Farzan Institute of Research and Technology for their generous involvement in the completion of this study.
8. Radiation-emitting products. < www.fda.gov/ radiationemittingproducts/resourcesforyouradiationemittingproducts/ ucm252761.htm> (Accessed March 12, 2014).

9. Center for Device and Radiological Health. U.S. Food and Drug Administration. Radiation-Emitting Product Code: NHN. $<$ www.accessdata.fda.gov/scripts/cdrh/cfdocs/cfPCD_rh/ classification.cfm?PCD =NHN> (Accessed March 12, 2014).

10. Bjordal JM, Johnson MI, Iversen V, Aimbire F, Lopes-Martins RA. Low level laser therapy in acute pain: A systemic review of possible mechanisms of action and clinical effects in randomized placebocontrolled trials. Photomed Laser Surg 2006;24:158-68.

11. Bjordal JM, Johnson MI, Iversen V, Aimbire F, Lopes-Martins RA. Photoradiation in acute pain: A systematic review of possible mechanisms of action and clinical effect in randomized placebocontrolled trials. Photomed Laser Surg 2006;24:158-6.

12. Bjordal JM, Lopes-Martins RA, Joensen J, et al. A systematic review with procedural assessment and meta-analysis of low level laser therapy in lateral elbow tendinopathy (tennis elbow). BMC Musculosketal Disorder 2008;9:75.

13. Hegedus B, Viharos L, Gervain M, Galfi M. The effect of low-level laser in knee osteoarthritis: A double-blind, randomized, placebocontrolled trial. Photomed Laser Surg 2009;27:577-84. 
14. Jackson RF, Roche G, Mangione T. Low-level laser therapy effectiveness for reducing pain after breast augmentation. Am J Cosmet Surg 2009;26.

15. Spinola A, Aguria MC, Grmo MA. 660 AsGaAl laser to alleviate pain caused by cryosurgical treatment of oral loukoplakia: A preliminary study. Photomed Laser Surg 2011;29:345-50.

16. Moore KC, Hira N, Broome IJ, Cruikshank JA. The effect of infrared dioxide laser irradiation on the duration and severity of postoperative pain: A double blind trial. Laser Ther 1992;4:145-8.

17. E Lima MT, E Lima JG, de Andrade MF, Bergmann A. Low-level laser therapy in secondary lymphedema after breast cancer: Systematic review. Lasers Med Sci 2012 [Epub ahead of print].

18. Omar MT, Shaheen AA, Zafar H. A systematic review of the effect of low-level laser therapy in the management of breast cancerrelated lymphedema. Support Care Cancer 2012;20:2977-84.
19. Singer AJ, Weeks R, Regev R. Laser-assisted anesthesia reduces the pain of venous cannulationin children and adults: A randomized controlled trial. Acad Emerg Med 2006;13: 623-8.

20. Singer AJ, Regev R, Weeks R, Tlockowski DS. Laser-assisted anesthesia prior to intravenous cannulation in volunteers. Acad Emerg Med 2005;12:804-7.

21. Koszowski R, Smieszek-Wilczewska J, Dawiec G. Comparison of analgesic effect of magnetic and laser stimulation before oral surgery procedures. Wiad Lek 2006;59:630-3.

22. Jonsson L. Preoperative low level laser application to reduce postoperative pain in patients receiving winograd type of partial matrixectomy surgery of hallux. < http://www.laser.nu/lllt/lllt editorial13.htm> (Accessed June 9, 2014). 


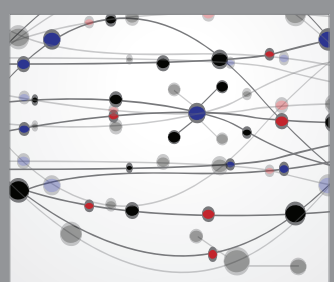

The Scientific World Journal
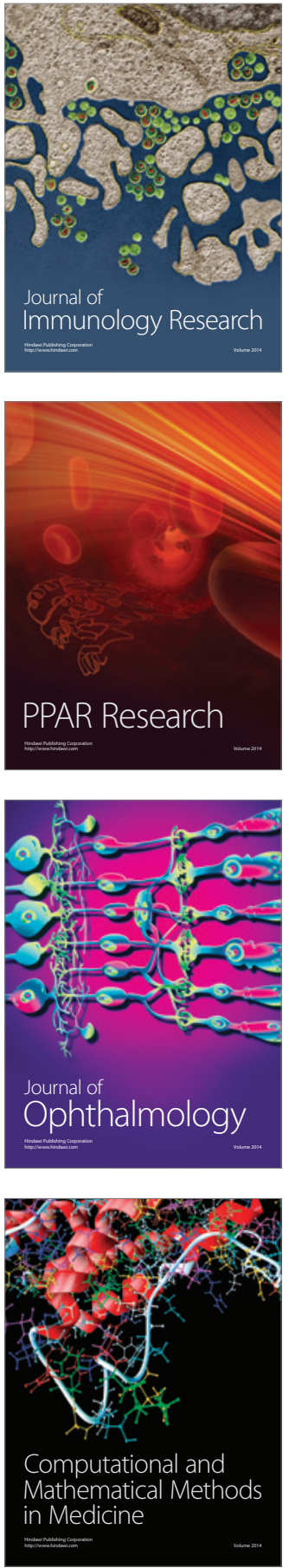

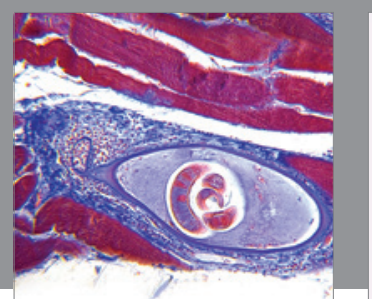

Gastroenterology Research and Practice

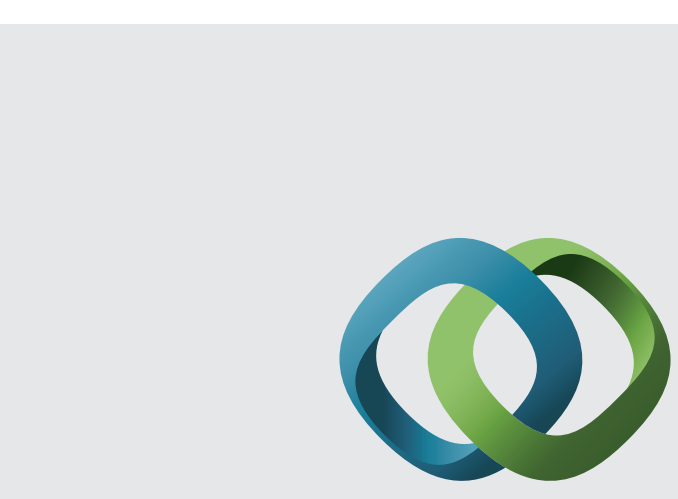

\section{Hindawi}

Submit your manuscripts at

http://www.hindawi.com
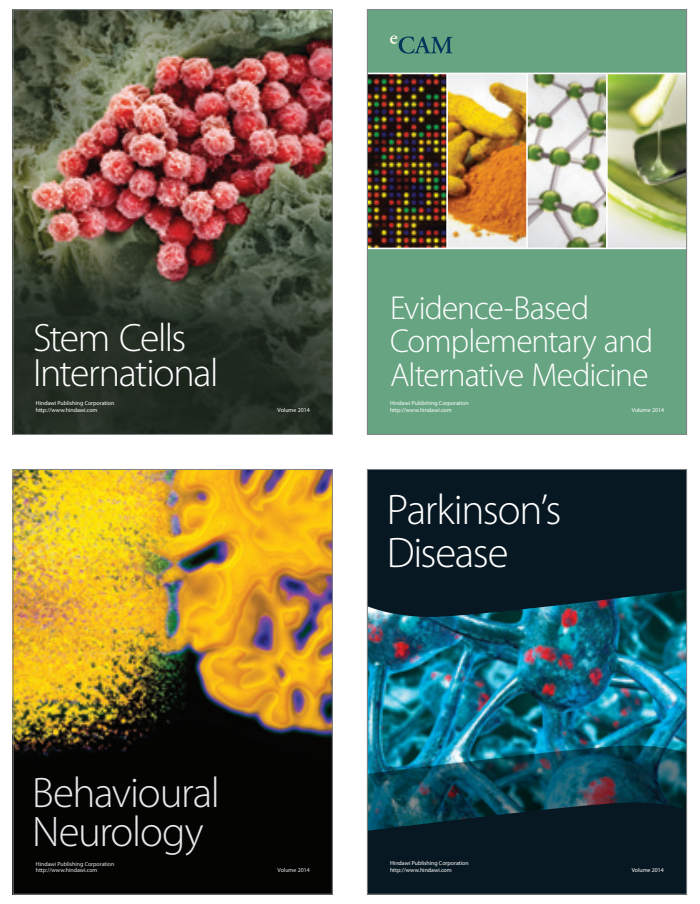
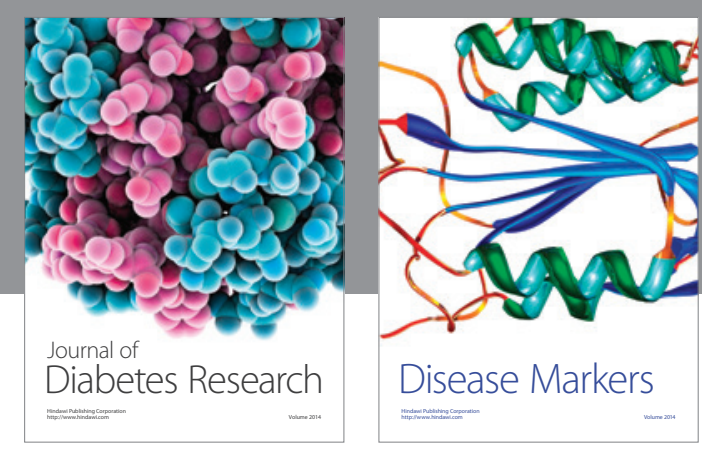

Disease Markers
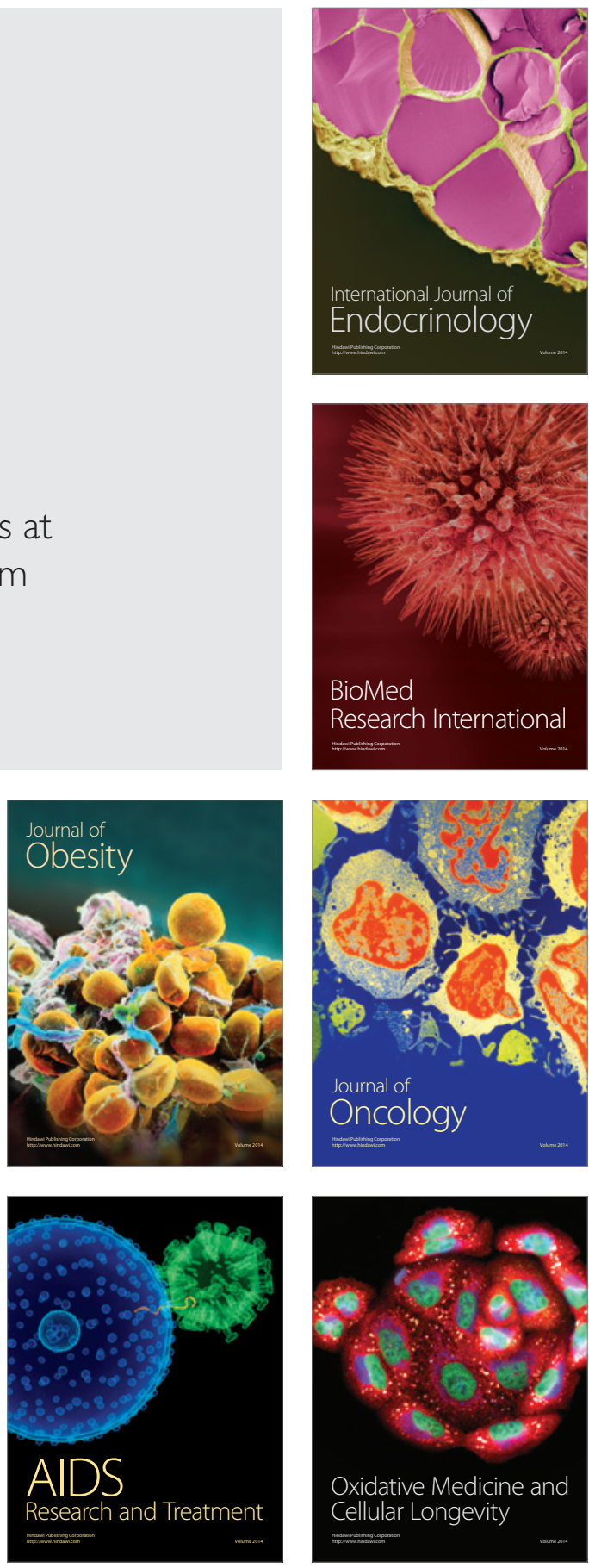